\title{
Volatility Discovery Across Stock Limit Order Book And Options Markets
}

\author{
QIN WANG*
}

\begin{abstract}
Foucault [Journal of Financial Markets, 2, 99-134, 1999] provides a theoretical basis for how stock price volatility influences the aggressiveness of limit order traders. I investigate volatility discovery across stock limit order book and options markets using a broad panel of NYSE-listed stocks from November 2007 to January 2008 and find strong evidence that, as predicted, the aggressiveness of the stock limit order book and option volatility trading Granger-cause each other. Further, I find that the aggressiveness of the stock limit order book and option volatility trading are inversely related, which is both statistically and economically significant. (C) 2013 Wiley Periodicals, Inc. Jrl Fut Mark 34:934-956, 2014
\end{abstract}

\section{INTRODUCTION}

Although price discovery across stock and options markets is a subject of widespread interest (see, e.g., Amin \& Lee, 1997; Anthony, 1988; Cao, Chen, \& Griffin, 2005; Chakravarty, Gulen, \& Mayhew, 2004; Easley, O’Hara, \& Srinivas, 1998; Kumar, Sarin, \& Shastri, 1992; Manaster \& Rendleman, 1982; Pan \& Poteshman, 2006; Schlag \& Stoll, 2005), evidence on cross-market volatility discovery is sparse (Lamoureux \& Lastrapes, 1993; Ni, Pan, \& Poteshman, 2008). ${ }^{1}$ Further, Ranaldo (2004) and Foucault, Moinas, and Theissen (2007) find that stock limit orders are informative for future stock price volatility. Foucault (1999) provides a theoretical basis for how stock price volatility influences the aggressiveness of limit order traders and finds that higher volatility subjects limit order submitters to higher picking off risk, thus forcing them to price their limit orders less aggressively. These seminal papers

Qin Wang is an Assistant Professor of Finance, College of Business, University of Michigan-Dearborn. I thank Thierry Foucault, Kenneth Kavajecz, Chris Lamoureux (dissertation chair), Nitish Ranjan Sinha (2011 FMA Discussant), Erik Theissen, Bob Webb (the editor), one anonymous referee, and seminar participants at the University of Arizona, California State University Fullerton, the Office of the Comptroller of the Currency Risk Analysis Division, University of Michigan-Dearborn, State University of New York at Albany, and Oakland University for helpful comments and suggestions. I thank the financial support from University of Michigan Dearborn for obtaining the data used in this paper. Finally, I thank Yufang Xia, Moxin Wang, Jun Zhang, and Elena ZhangWang for support.

${ }^{*}$ Correspondence author, College of Business, University of Michigan-Dearborn, Fairlane Center South, 19000 Hubbard Drive, Dearborn, MI 48126-2638. Tel: +313-583-6487, Fax: +313-271-9837, e-mail: qinw@umich.edu

Received April 2012; Accepted April 2013

\footnotetext{
${ }^{1}$ Although a few studies find that option trading is unlikely to be informed (see, e.g., Chan, Chung, \& Fong, 2002; Stephan \& Whaley, 1990; Vijh, 1990), evidence overwhelmingly favors the opposite. In a dynamically complete market setting, Black and Scholes (1973) view options as redundant securities. Reasons as to why option trading could be informed include higher leverage effect (Black, 1975), avoiding short sale constraints (Figlewski \& Webb, 1993), hiding in a variety of option contracts (Easley et al., 1998), and lower transaction costs (see, e.g., Manaster \& Rendleman, 1982; Mayhew, Sarin, \& Shastri, 1995; Chakravarty et al., 2004).
} 
suggest important potential channels related to the state of the limit order book through which cross-market volatility discovery occurs.

However, there is no systematic evidence in this regard. My study aims to answer this question by analyzing a sample of stocks with data on both the stock limit order book and option trading with the research design being different from previous literature in that I analyze how aggressiveness of the stock limit order book and option volatility trading interact with each other in cross-market volatility discovery. I find striking evidence that cross-market volatility discovery occurs through the dynamics between the aggressiveness of the stock limit order book and option volatility trading.

The intuition behind my research design derives from the fact that limit orders, although free of price risk, do not have guaranteed execution and are susceptible to picking off risk. Picking off risk is different from the adverse selection risk (Bagehot, 1971) in that the former arises when quotes do not timely reflect all available public information, and the latter arises when some traders possess private information not currently reflected in security prices. ${ }^{2}$ The fact that limit orders are exposed to picking off risk is noted by Copeland and Galai (1983).

Parlour and Seppi (2008) point out that it is because of these two kinds of risk that limit order books should contain forward-looking information about future market conditions. Contrary to the old wisdom that limit orders are uninformed whereas market orders are informed (see, e.g., Glosten, 1994; Glosten \& Milgrom, 1985; Kyle, 1985), recent work on limit orders finds that informed traders tend to use limit orders (see, e.g., Anand, Chakravarty, \& Martell, 2005; Bloomfield, O'Hara, \& Saar, 2005; Kaniel \& Liu, 2006), and that limit orders are informative for future liquidity (Kavajecz \& Odders-White, 2004), for directions of future stock price movements (see, e.g., Biais, Hillion, \& Spatt, 1995; Cao, Hansch, \& Wang, 2009; Harris \& Panchapagesan, 2005), and for future stock price volatility (Ranaldo, 2004; Foucault et al., 2007). The popularity of limit order trading indicates that the cost of being possibly picked off together with the execution uncertainty has to be compensated by some forms of trading gains from using limit orders (see, e.g., Glosten, 1994; Handa \& Schwartz, 1996), which is confirmed empirically by Harris and Hasbrouck (1996) and Hollifield, Miller, Sandås, and Slive (2006).

In the presence of informed trading, one common prediction from theoretical models of Glosten (1994), and Seppi (1997) is that investors submitting limit orders are subject to a winner's curse, namely limit order non-execution risk is negatively related to the probability of incurring a loss. ${ }^{3}$ Besides, consistent with Griffiths, Smith, Turnbull, and White (2000), Ranaldo (2004), and Aitken, Almeida, Harris, and McInish (2007) provide supporting empirical evidence that the stock limit order traders' monitoring costs and the level of patience affect the tradeoff between picking off and non-execution risk, and thus price aggressiveness of the stock limit order book.

The implications of these two strands of literature are as follows. First, stock limit order submitters can adjust the aggressiveness of stock limit order submissions based on volatility signals from volatility-related option volumes whereas option traders can adjust option volatility trading based on predicted future changes in stock price volatility inferred from the aggressiveness of the stock limit order book. In other words, the aggressiveness of stock limit

\footnotetext{
${ }^{2}$ Berkman (1996) shows that option market limit orders on the European Options Exchange in Amsterdam are commonly picked off after the underlying stock's price changes. The implication being that professional traders are able to exploit these limit orders as the individuals who placed them cannot revise them quickly in the face of new information. Linnainmaa (2010) looks at Finnish data, and finds that the documented poor performance of retail traders may be attributed to their use of limit orders.

${ }^{3}$ Cho and Nelling (2002), Ahn, Bae, and Chan (2001), Hasbrouck and Saar (2002), and Lo, MacKinlay, and Zhang (2002) provide empirical evidence that non-execution risk is negatively related to stock price volatility.
} 
orders and option volatility trading are informative for each other. Further, the aggressiveness of stock limit orders is likely to be inversely related to option volatility trading.

To test the hypotheses, I first investigate whether the aggressiveness of the stock limit order book and option volatility trading are informative for predicting each other. Mounting evidence suggests that stock limit order traders are likely to trade in response to option volatility trading and that option volatility traders are likely to trade on the aggressiveness of the stock limit order book. I use the vector autoregression to examine the dynamic relationship between the aggressiveness of the stock limit order book and option volatility trading. In particular, I investigate whether there is a causal link in the Granger $(1969,1980)$ sense between the two and find that the two are informative for predicting each other.

Next, I analyze how the aggressiveness of the stock limit order book and option volatility trading are related to each other. As discussed earlier, Foucault (1999) shows that higher volatility increases the picking off risk for limit orders, thus making limit order traders trade less aggressively. This implies that the aggressiveness of the stock limit order book and option volatility trading are inversely related. I examine plots of impulse response functions from the vector autoregression and find supporting evidence with both statistical and economical significance.

I make two major contributions to the literature. First, I increase understanding of mechanisms of volatility trading across the stock and options markets. To the best of my knowledge, this is the first paper to identify new mechanisms of cross-market volatility discovery using the state of the stock limit order book. In particular, I show that the aggressiveness of the stock limit order book and option volatility trading Granger-cause each other. Further, I show that the two are inversely related. By explicitly taking into account the informational role of the state of the stock limit order book in cross-market volatility trading, my study provides new insight into how dynamics of volatility discovery takes place. My results indicate that it is also important to consider the role of the stock limit order book in cross-market volatility discovery.

The rest of the paper is organized as follows. Section 2 develops hypotheses. Section 3 discusses variable constructions, methodological issues, and the sample. Section 4 presents empirical analysis. Section 5 provides robustness checks. Section 6 concludes this study.

\section{HYPOTHESES}

Prior studies suggest that stock limit order submitters can infer volatility signals from volatility-related option volumes and thus adjust the aggressiveness of stock limit orders accordingly during submissions. Similarly, option traders can infer future changes in stock price volatility from the aggressiveness of the stock limit order book and thus perform option volatility trading accordingly. My first hypothesis can be stated as follows:

H1: The aggressiveness of the stock limit order book and option volatility trading are informative for predicting each other.

Conditional on heightened option volatility trading, a signal of increasing future stock price volatility, volatility-informed stock traders would place stock limit orders less aggressively due to increased picking off risk, lower non-execution risk, and increased monitoring costs. On the other hand, volatility-informed stock traders would interpret decreasing option volatility trading as a signal of decreasing future stock price volatility and thus would become more aggressive in limit order submissions. By the same token, conditional on a decrease in the aggressiveness of stock limit order book, a signal of increasing future stock price volatility, volatility-informed option traders would increase volatility buying activities including buying calls and/or puts and decrease volatility selling activities including 
selling calls and/or puts. By contrast, an increase in the aggressiveness of stock limit order book would signal decreasing future stock price volatility and volatility-informed option traders would decrease volatility buying activities and increase volatility selling activities. My second hypothesis can thus be stated as follows:

$\mathrm{H} 2$ : The aggressiveness of the stock limit order book is negatively related to option volatility buy and positively related to option volatility sell.

The empirical prediction of the first hypothesis is that the aggressiveness variables of the stock limit order book and the option volatility trading variables Granger-cause each other and the empirical prediction of the second hypothesis is that option traders would increase option volatility buying activities and decrease option volatility selling activities in response to a decrease in the aggressiveness of stock limit order book and would decrease option volatility buying activities and increase option volatility selling activities in response to an increase in the aggressiveness of stock limit order book.

\section{VARIABLE CONSTRUCTIONS, METHODOLOGIES, AND DATA}

\subsection{Variable Constructions}

To examine the linkages between the aggressiveness of the stock limit order book and option volatility trading, I construct stock aggressiveness variables and option volatility trading variables.

Based on Biais et al. (1995) that the aggressiveness is in terms of both order size and price position relative to the prevailing quotes, I use the following three steps to construct the aggressiveness variables for the stock limit order book. First, I estimate snapshots of the stock limit order book at 5-minute intervals using the technique similar to that described in Kavajecz (1999). Next, I calculate the total depth on each side of the limit order book and the ratio of the depth at each price step to the total same-side depth of the book. Third, I take the weighted average of the depth ratios on each side of the book, with the weight being the inverse of the absolute value of the difference between the corresponding price and the prevailing midpoint of the inside spread on the limit order book. Hence, I construct StockAggressiveBuy and StockAggressiveSell to measure the aggressiveness of the stock limit order book on the buy and sell sides, respectively.

Stale limit orders are not state-contingent and are thus subject to picking off risk. If ever executed, stale limit orders are executed adversely. For those stale limit orders not adversely executed, they are usually submitted far away from the market. For example, a limit order trader can submit a good-to-cancelled order to buy at an infinitesimally low price which is unlikely to get executed and thus remains on the limit order book for a long time. Because the weight used for the unexecuted stale limit order is small as the weight is the inverse of the absolute value of the difference between the limit order price and prevailing market quote, the overall effect of unexecuted stale limit orders on the aggressiveness variables of the stock limit order book is marginal at best. Further, relatively low liquidity companies with less transparency have more unexecuted stale orders and thus the existence of such orders works against finding evidence of dynamic changes in the aggressiveness of the stock limit order book and option volatility trading. So results reported are conservative.

I construct option volatility trading variables based on the following thoughts. Buying calls and buying puts are increasing functions of stock price volatility. Besides, buying calls and buying puts react in the opposite direction to the same change in stock price movement, which means that option delta trading can be mostly eliminated by aggregating buying calls 
and buying puts. Further, different classes of options have different sensitivities to stock price volatility and volatility-informed investors are more likely to trade option contracts with higher vegas. ${ }^{4}$ Hence, I construct an option volatility buying variable, OptionVolatilityBuy, by first weighting each option contract by its vega and then summing the vega-weighted number of buyer-initiated call and put contracts. By the same token, I construct an option volatility selling variable, OptionVolatilitySell, by first weighting each option contract by its vega and then summing the vega-weighted number of seller-initiated call and put contracts. By construction, option volatility trading variables are not correlated with option delta trading and thus capture true volatility demand.

Figure 1 provides an illustration of the aggressiveness of the stock limit order book and option volatility trading variables. This figure plots average normalized variables for the 78 five-minute intervals throughout one trading day for the whole sample. The upper left and right panels display StockAggressiveBuy and StockAggressiveSell, respectively. The lower left and right panels display OptionVolatilityBuy and OptionVolatilitySell, respectively. For example, the aggressiveness of both buy and sell sides of the stock limit order book increase at a decreasing rate at the beginning of the trading day, remain almost constant during the day, and increase dramatically at the very end of the trading day. ${ }^{5}$

\subsection{Methodologies}

My goal is to examine the possible volatility linkages, if any, between the aggressiveness of the stock limit order book and option volatility trading. For a given high-volatility signal, volatility-informed stock traders might place limit orders less aggressively due to increased picking off risk, whereas volatility-informed option traders might increase buying calls and puts, and/or decrease selling calls and puts. In contrast, for a given low-volatility signal, the reverse might be true. Hence, bivariate Granger-causality is likely, which motivates the vector autoregression (VAR) methodology.

There are several issues that must be addressed before using the VAR. First, following Stephan and Whaley (1990) and Easley et al. (1998) that examine the linkages across the stock and options markets, I partition each trading day (9:30 am EST to 4:00 pm EST) into 78 five-minute intervals. I extract aggressiveness variables of the stock limit order book from the limit order book snapshots estimated at 5-minute intervals using the technique similar to that described in Kavajecz (1999). I obtain option volume series by aggregating relevant option contracts within each 5-minute interval. To control for cross-sectional variations across different stocks and options, I normalize each series by subtracting the mean and dividing by the standard deviation for each day, which allows me to pool the 529 stocks together and to increase the power of the tests. Finally, I conduct augmented Dickey-Fuller tests on all four normalized series including two stock aggressiveness series and two option volume series allowing for individual intercepts, and use information criteria to select the number of

\footnotetext{
${ }^{4}$ I calculate vega based on methods proposed in Cox, Ross, and Rubinstein (1979). I first build a recombining binomial stock tree with discrete dividends, and value American options on the tree by applying the backward induction technique. I then rebuild the binomial stock tree with a small increase in volatility and value options similarly as before. Vega is then approximated by the ratio of change in option value with respect to volatility.

${ }^{5}$ It is interesting to note that at the end of the day, both StockAggressiveBuy and StockAggressiveSell increase abruptly. One plausible explanation is that since majority of the limit orders are good till market close on the NYSE, so when the market is approaching closing time, good-till-market-close limit orders become much more aggressive to try to get last-minute execution. Please refer to Bae, Jang, and Park (2003) for a description of order type percentage breakdowns for the 144 NYSE stocks in the TORQ database from November 1990 to January 1991. Informal talks with the data provider also indicate that majority of the limit orders are good till market close on the NYSE for my sample period. However, the abrupt increase in aggressiveness does not impact the intraday relationship between aggressiveness and volatility variables as shown in the following empirical analysis.
} 

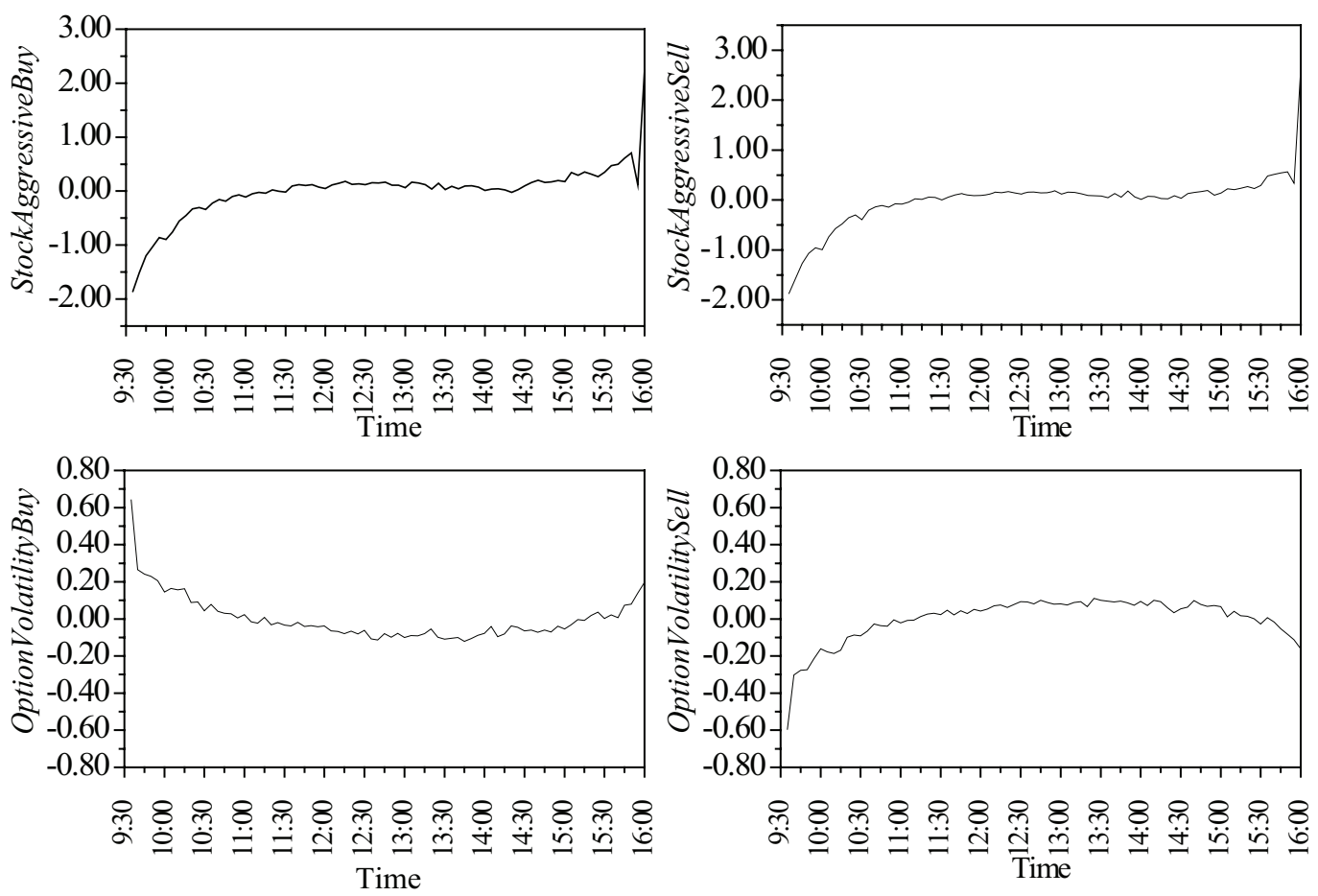

FIGURE 1

Normalized aggressiveness of the stock limit order book and option volatility trading variables. Note. This figure plots average normalized aggressiveness variables of the stock limit order book and option volatility trading variables for the 78 five-minute intervals throughout one trading day for the 529 stocks in both the NYSE OpenBook History (Openbook) database and the Options Price Reporting Authority (OPRA) database between November 1, 2007 and January 31, 2008. See Table I for variable definitions.

augmentation lags. I reject the existence of a unit root at $P$ values less than 0.0001 . Thus, all the normalized series are stationary and are then used in the VAR analysis.

To explore the direction of the effects of shocks on the aggressiveness of the stock limit order book and option volatility trading, I consider a four-equation vector autoregression that incorporates four variables including two aggressiveness variables from the stock limit order book and two option volatility trading variables. Specifically, I use the following system:

$$
\begin{aligned}
S_{t} & =\sum_{i=1}^{K} \alpha_{i} S_{t-i}+\sum_{i=1}^{K} \beta_{i} O_{t-i}+u_{t}, \\
O_{t} & =\sum_{i=1}^{K} \gamma_{i} S_{t-i}+\sum_{i=1}^{K} \delta_{i} O_{t-i}+\varepsilon_{t}
\end{aligned}
$$

where $S_{t}$ is a 2 by 1 vector that represents the aggressiveness of the buy and sell sides of the stock limit order book, $O_{t}$ is a 2 by 1 vector that represents the option volatility trading, and $K$ is the number of lags. In my empirical estimation, I choose $K$ based on the Akaike, Schwartz, and Hannan-Quinn information criteria. If these three criteria indicate different lag lengths, I choose the lesser one for the sake of parsimony.

Based on estimates of the VARs, I calculate impulse response functions and examine how the endogenous variables react with each other over time. An impulse response function 
traces the effect of a one-time one standard deviation shock to one of the innovations on current and future values of the endogenous variables through the dynamic structure of the VAR. If innovations are correlated, they need to be orthogonalized first. I use the inverse of the Cholesky decomposition of the residual covariance matrix to orthogonalize the impulses. Although impulse response functions trace the effects of a shock to one endogenous variable on the other variables in the VAR, variance decomposition decomposes variation in an endogenous variable into the component shocks to the endogenous variables in the VAR. The source of this forecast error is the variation in the current and future values of the innovations to each endogenous variable in the VAR.

Results on impulse response functions and variance decompositions are generally contingent on the specific orderings of the endogenous variables. Unreported results show that my findings are robust to the ordering of endogenous variables. In the following analysis, the stock aggressiveness variables are placed before the option volatility trading variables unless otherwise noted.

\subsection{Data}

I use several data sources for this paper. I construct the aggressiveness variables of the stock limit order book from the NYSE OpenBook History (Openbook) database, which provides the aggregate limit-order volume at every bid and offer price for all NYSE-traded securities throughout each trading day. I extract option volume from the Options Price Reporting Authority (OPRA) database, which contains a complete record of quote and trade prices of options traded on all U.S. options exchanges time-stamped to the nearest second. Data on ex-dividend dates and daily cash dividends are from the Center for Research in Security Prices (CRSP) database. I hand collect ask yields of daily Treasury bills matching maturities of options from the Bloomberg as risk-free rates. I obtain data on high-frequency quote and trade at 5-minute intervals from the trade and quote (TAQ) database. My sample period is from November 1, 2007, to January 31,2008 , since it is a relatively quiet time period which allows full and normal interplay among variables of interest.

I delete stocks in financial service (SIC 6,000-6,999), stocks in regulated utilities (SIC $4,800-4,829$ and 4,910-4,949), foreign stocks, stocks with prices less than $\$ 5$, stocks that split, and stocks that experience mergers and acquisitions during my sample period. I also delete stocks with no data in TAQ.

Following Lee and Ready (1991) and Easley et al. (1998), I pair each trade with the most recent quote that is no older than 30 minutes, and proceed in the following steps for trade classification. First, a trade occurring above (below) the midpoint is classified as a buy (sell). Second, a trade occurring at the midpoint with the current trade price being higher (lower) than its previous one is classified as a buy (sell), which is the "tick test." Finally, a trade occurring at the midpoint with the current trade price being the same as its previous one is classified as a buy (sell) if the previous price is higher (lower) than its previous one, which is the "zero-tick test." Trades that cannot be classified using the above steps are discarded.

I apply the following exclusion filters to the option data. I discard quotes not satisfying the no-arbitrage restrictions. To mitigate the impact of tick size on option valuation, I exclude option quotes lower than $\$ 0.375$. To control for option hedging behavior, I exclude option trades with condition code $\mathrm{P} .{ }^{6}$ To avoid option expiration induced abnormal trading, I exclude option trades with less than or equal to a week to maturity. To alleviate possible biases induced by thin trading, I exclude option-stock days with less than or equal to 50 option trades per day.

\footnotetext{
${ }^{6}$ Option trades with condition code $\mathrm{P}$ represent the option portion of an order involving a single option leg (buy or sell
} of a call or a put) and stock. 
To control for ex-dividend effects, I exclude option trades on ex-dates of underlying stocks. To avoid stock split induced abnormal trading, I exclude option trades on split days of underlying stocks. To eliminate nonsynchronicity in trading of options and stocks, I exclude option trades that are time-stamped after 3:00 pm CST. To mitigate possible mistakes of reporting multiple trades for one large trade with multiple counterparties, I aggregate option trades occurring within 5 seconds of each other with the same trade price, same trade direction, and same prevailing quotes into one trade.

Taking the intersection of the filtered stock limit order data and option trades data leaves 529 firms with 6,889 pairs of option-stock days.

I reconstruct each stock's limit order book using the technique similar to that described in Kavajecz (1999). I start with the provided snap shot of the limit order book as of the close of operation of the open book system on the previous day, select incremental changes to the number of shares for each price point for each stock before the chosen time, sum shares by price point on buy and sell sides, and eliminate price points where the aggregate number of shares is 0 . The remaining set of orders is thus the limit order book estimate for the chosen time on that day. I sequentially update limit order book estimates every 5 minutes till 4:00 pm EST, resulting in 78 limit order book estimates each day for each stock. ${ }^{7}$

\section{EMPIRICAL ANALYSIS}

Before formally examining the volatility discovery across the aggressiveness of the stock limit order book and option volatility trading, Table I reports summary statistics of the variables of interest.

Statistics in Table I are reported before normalization. Panel A of Table I shows that over my sample period mean and median StockAggressiveBuy are 4.89 and 3.80, respectively, whereas mean and median StockAggressiveSell are 3.39 and 2.78, respectively. This indicates that the stock limit order book shows slightly more aggressiveness on the buy side than on the sell side. Panel B of Table I shows that mean and median OptionVolatilitySell (165.08; 17.73) are bigger than those for OptionVolatilityBuy (162.00; 14.82), respectively. This indicates that, on average, selling calls and/or puts is slightly more than buying calls and/or puts.

I now turn to empirical investigations of volatility discovery across the aggressiveness of the stock limit order book and option volatility trading.

\subsection{Pairwise Granger-Causality Tests}

Table II reports the results of the pairwise Granger-causality tests using three 5-minute lags. Consistent with the prediction of the hypothesis, I observe that the feedback effect exists between the aggressiveness of the stock limit order book and option volatility trading. For example, the null hypothesis that StockAggressiveBuy does not Granger-cause OptionVolatilityBuy is rejected with a Wald test statistic of 83.145 , significant at the $1 \%$ level. This implies that StockAggressiveBuy Granger-causes OptionVolatilityBuy. Besides, the null hypothesis that OptionVolatilityBuy does not Granger-cause StockAggressiveBuy is rejected with a Wald test statistic of 30.949 , significant at the $1 \%$ level. This implies that OptionVolatilityBuy Granger-causes StockAggressiveBuy. Granger-causality runs in both directions between StockAggressiveBuy and OptionVolatilityBuy, which clearly indicates the feedback effect between the aggressiveness of the stock limit order book and option volatility trading.

\footnotetext{
${ }^{7}$ As pointed out by Aitken et al. (2007), snapshots approach is a research design free of systematic sampling bias for measuring the aggressiveness variables.
} 
TABLE I

Summary Statistics

\begin{tabular}{lccccc}
\hline Variable name & Mean & Median & SD & Min. & Max. \\
\hline Panel A: Summary statistics & for stock aggressiveness variables & & & \\
StockAggressiveBuy & 4.89 & 3.80 & 4.14 & 0.04 & 151.37 \\
StockAggressiveSell & 3.39 & 2.78 & 2.58 & 0.10 & 135.08 \\
Panel B: Summary statistics for & option trading & variables & & & \\
OptionVolatilityBuy & 162.00 & 14.82 & 1004.49 & 0.00 & 193139.51 \\
OptionVolatilitySell & 165.08 & 17.73 & 1066.60 & 0.00 & 152981.53 \\
\hline
\end{tabular}

Note. This table reports summary statistics of the aggressiveness variables of the stock limit order book and option volatility trading variables for the 529 stocks in both the NYSE OpenBook History (Openbook) database and the Options Price Reporting Authority (OPRA) database between November 1, 2007 and January 31, 2008. I use the following three steps to construct the aggressiveness variables for the stock limit order book. First, I estimate snapshots of the limit order book at 5-minute intervals using the technique similar to that described in Kavajecz (1999). Next, I calculate the total depth on each side of the limit order book and the ratio of the depth at each price step to the total same side depth of the book. Third, I take the weighted average of the depth ratios on each side of the book, with the weight being the inverse of the absolute value of the difference between the corresponding price and the prevailing midpoint of the inside spread on the limit order book. StockAggressiveBuy and StockAggressiveSell are the weighted averages of the depth at each price step on the buy and sell sides to the total same side depth of the book, respectively. Option trading variables are aggregated over 5-minute intervals. OptionVolatilityBuy is the total number of vega-weighted buyer-initiated option contracts. OptionVolatilitySell is the total number of vega-weighted seller-initiated option contracts. All series are before normalization.

Note that variable $i$ Granger-causing variable $\mathrm{j}$ does not imply that $i$ causes $j$ to happen. Granger-causality measures precedence and information content, namely, whether adding past values of one variable to an autoregressive model of the other variable improves the predictability of the other variable.

\subsubsection{Pairwise Granger-causality tests by time of day}

Foster and Viswanathan (1990) document larger trade impacts at the beginning and at the end of the day. This indicates that trading is more likely to be informed at the beginning and at the end of the day and that percentages of stocks with Granger-causality running in either or both directions between the stock aggressiveness and option volatility trading variables are bigger at the beginning and at the end of the day. To test this, I partition the trading day into the first 1 hour and a half trading $(9: 30 \mathrm{am}-11: 00 \mathrm{am})$, the middle day (11:00 am-2:30 pm), and the last 1 hour and a half trading $(2: 30 \mathrm{pm}-4: 00 \mathrm{pm})$. Table III

TABLE II

Pairwise Granger-Causality Tests

\begin{tabular}{lcccc}
\hline & StockAggressiveBuy & StockAggressiveSell & OptionVolatilityBuy & OptionVolatilitySell \\
\hline StockAggressiveBuy & & & 83.15 & 150.03 \\
StockAggressiveSell & & & 114.59 & 171.18 \\
OptionVolatilityBuy & 30.95 & 11.89 & & \\
OptionVolatilitySell & 37.00 & 16.59 & & \\
\hline
\end{tabular}

Note. This table reports the results from a VAR with endogenous variables in the order of StockAggressiveBuy, StockAggressiveSell, OptionVolatilityBuy, and OptionVolatilitySell. The VAR is estimated with three lags. Wald test statistics of pairwise Granger-causality tests between each aggressiveness variable of the stock limit order book and each option volatility trading variable are reported. The null hypothesis is that the row variable does not Granger-cause the column variable. All variables used have been normalized. All the Wald test statistics are significant at the $1 \%$ level. See Table I for variable definitions. 
TABLE III

Pairwise Granger-Causality Tests by Time of Day

\begin{tabular}{lllrr}
\hline Time interval & \multicolumn{1}{c}{ Stock variable } & Option trading variable & Stock to option & Option to stock \\
\hline 9:30 am-11:00 am & StockAggressiveBuy & Optionvolatilitybuy & 15.00 & 11.54 \\
& StockAggressiveBuy & OptionVolatilitySell & 14.04 & 9.04 \\
& StockAggressiveSell & OptionVolatilityBuy & 14.04 & 11.92 \\
& StockAggressiveSell & OptionVolatilitySell & 15.58 & 11.73 \\
11:00 am-2:30 pm & StockAggressiveBuy & OptionVolatilityBuy & 12.88 & 7.50 \\
& StockAggressiveBuy & OptionVolatilitySell & 10.00 & 6.54 \\
& StockAggressiveSell & OptionVolatilityBuy & 11.54 & 6.73 \\
& StockAggressiveSell & OptionVolatilitySell & 10.58 & 5.58 \\
2:30 pm-4:00 pm & StockAggressiveBuy & OptionVolatilityBuy & 15.77 & 10.38 \\
& StockAggressiveBuy & OptionVolatilitySell & 14.42 & 13.27 \\
& StockAggressiveSell & OptionVolatilityBuy & 13.65 & 13.65 \\
& StockAggressiveSell & OptionVolatilitySell & 14.04 & 15.96 \\
\hline
\end{tabular}

Note. This table reports the percentages of the stocks in the sample with statistically significant Granger-causality at the $5 \%$ level based on F-tests using three lags by time of day. The sample includes the 529 stocks in both the NYSE OpenBook History (Openbook) database and the Options Price Reporting Authority (OPRA) database between November 1 , 2007 and January 31, 2008. "Stock to Option" means the aggressiveness variables of the stock limit order book Granger-causing the option volatility trading variables. "Option to Stock" means the option volatility trading variables Granger-causing the aggressiveness variables of the stock limit order book. All variables used have been normalized. See Table I for variable definitions.

reports the percentages of the stocks in the sample with statistically significant Granger-causality at the $5 \%$ level based on F-tests using three lags by time of day. "Stock to Option" means the stock aggressiveness variables Granger-causing the option volatility trading variables. "Option to Stock" means the option volatility trading variables Granger-causing the stock aggressiveness variables. Consistent with the prediction from Foster and Viswanathan (1990), results in Table III show that the percentages of stocks in the categories of both "Stock to Option" and "Option to Stock" are higher at the beginning and at the end of the day. For example, StockAggressiveBuy Granger-causes OptionVolatilityBuy in $15 \%$ and $16 \%$ of the sample stocks at the beginning and at the end of the day, but in $13 \%$ of the sample stocks at the middle of the day.

\subsubsection{Pairwise Granger-causality tests by time of day and bid-ask spread}

Further, I sort sample stocks into terciles by decreases in the inside bid-ask spread on the snapshot of the stock limit order book at the beginning of November 1, 2007. Table IV reports results in this regard. I find that the percentage of stocks in the category of "Stock to Option" is generally bigger for large than for small bid-ask spread at the beginning and at the end of the trading day. For example, at the end of the trading day, StockAggressiveBuy Granger-causes OptionVolatilityBuy in $5 \%$ of the sample stocks for large bid-ask spread, and in $4 \%$ of the sample stocks for small bid-ask spread, respectively. I do not observe the similar patterns for the middle day trading.

Consistent with the results in Table III, I find that percentages of stocks in the category of "Stock to Option" at the beginning and at the end of the trading day are larger when bid-ask spread is large or medium in Table IV. It is also evident from Table IV that the percentage of stocks in "Stock to Option" is bigger than that in "Option to Stock.” 
TABLE IV

Pairwise Granger-Causality Tests by Time of Day and Bid-Ask Spread

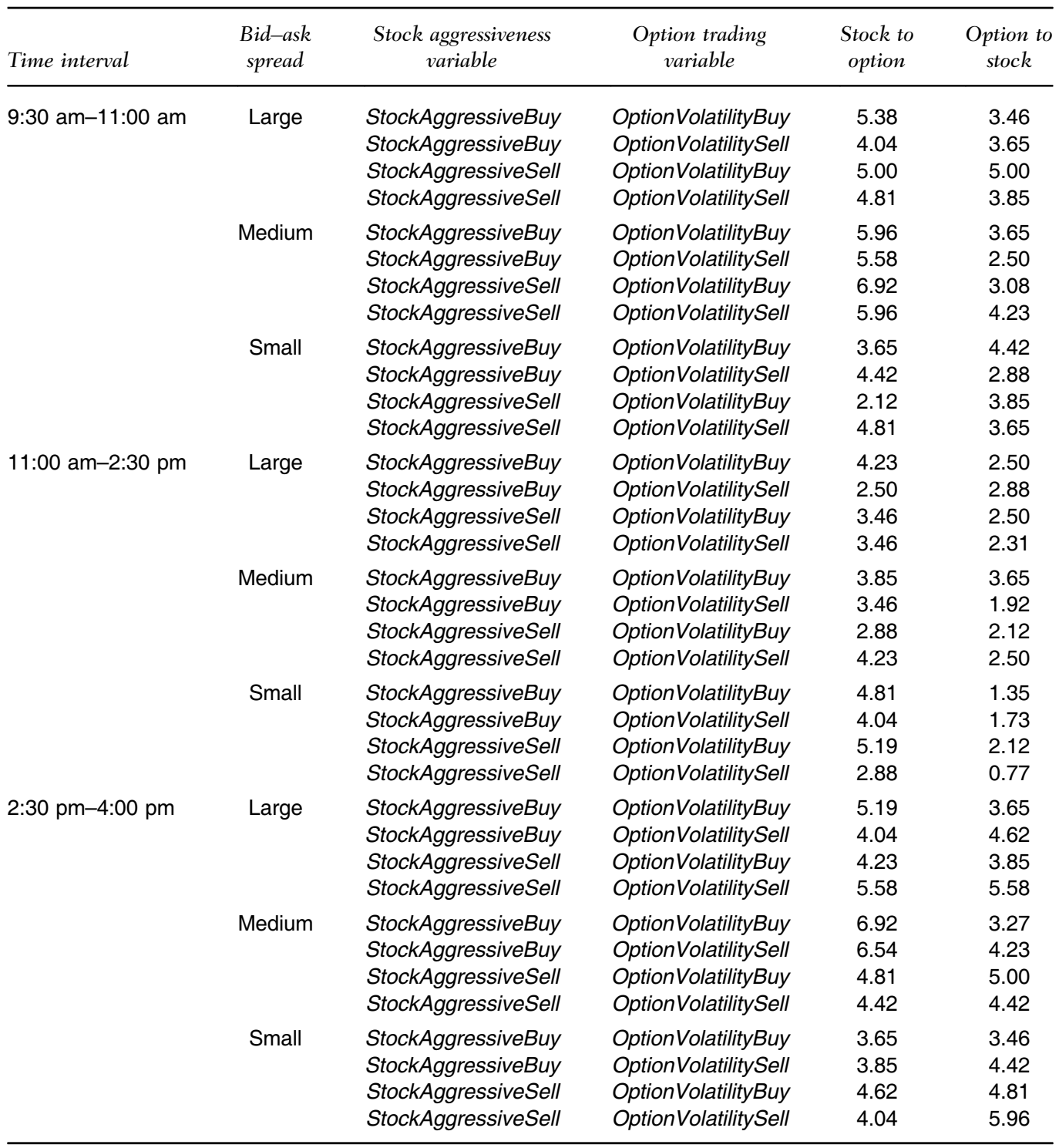

Note. This table reports the percentages of the stocks in the sample with statistically significant Granger-causality at the $5 \%$ level based on F-tests using three lags by time of day and bid-ask spread. The sample includes the 529 stocks in both the NYSE OpenBook History (Openbook) database and the Options Price Reporting Authority (OPRA) database between November 1, 2007 and January 31, 2008. The 529 stocks are sorted into terciles by decreases in the inside bid-ask spread on the snapshot of the stock limit order book at the beginning of November 1, 2007. "Stock to Option" means the aggressiveness variables of the stock limit order book Granger-causing the option volatility trading variables. "Option to Stock" means the option volatility trading variables Granger-causing the aggressiveness variables of the stock limit order book. All variables used have been normalized. See Table I for variable definitions.

\subsubsection{Pairwise Granger-causality tests by option moneyness}

Table $\mathrm{V}$ reports the percentages of stocks in the sample with statistically significant Granger-causality at the $5 \%$ level based on F-tests using three lags by option moneyness. I define, respectively, in-the-money (ITM) options as call options with moneyness less than 
TABLE V

Pairwise Granger-Causality Tests by Option Moneyness

\begin{tabular}{llccc}
\hline Moneyness & Stock variable & Option trading variable & Stock to option & Option to stock \\
\hline ATM & StockAggressiveBuy & OptionVolatilityBuy & 16.15 & 10.58 \\
& StockAggressiveBuy & OptionVolatilitySell & 18.65 & 9.42 \\
& StockAggressiveSell & OptionVolatilityBuy & 14.81 & 12.12 \\
& StockAggressiveSell & OptionVolatilitySell & 17.12 & 7.88 \\
ITM & StockAggressiveBuy & OptionVolatilityBuy & 12.69 & 8.46 \\
& StockAggressiveBuy & OptionVolatilitySell & 13.46 & 10.00 \\
& StockAggressiveSell & OptionVolatilityBuy & 15.00 & 11.54 \\
& StockAggressiveSell & OptionVolatilitySell & 16.15 & 9.81 \\
OTM & StockAggressiveBuy & OptionVolatilityBuy & 12.88 & 10.38 \\
& StockAggressiveBuy & OptionVolatilitySell & 12.50 & 11.92 \\
& StockAggressiveSell & OptionVolatilityBuy & 13.46 & 9.62 \\
& StockAggressiveSell & OptionVolatilitySell & 13.27 & 10.77 \\
\hline
\end{tabular}

Note. This table reports the percentages of the stocks in the sample with statistically significant Granger causality at the $5 \%$ level based on F-tests using three lags by option moneyness. The sample includes the 529 stocks in both the NYSE OpenBook History (Openbook) database and the Options Price Reporting Authority (OPRA) database between November 1, 2007 and January 31, 2008. I define, respectively, in-the-money options as call options with moneyness less than 0.95 and put options with moneyness more than 1.05, out-of-the-money options as call options with moneyness greater than 1.05 and put options with moneyness less than 0.95 , at-the-money options with moneyness between 0.95 and 1.05 , inclusively. "Stock to Option" means the aggressiveness variables of the stock limit order book Granger-causing the option volatility trading variables. "Option to Stock" means the option volatility trading variables Granger-causing the aggressiveness variables of the stock limit order book. All variables used have been normalized. See Table I for variable definitions.

0.95 and put options with moneyness more than 1.05, out-of-the-money (OTM) options as call options with moneyness greater than 1.05 and put options with moneyness less than 0.95, at-the-money (ATM) options with moneyness between 0.95 and 1.05, inclusively. Results in Table V show that percentages of stocks in the category of "Stock to Option" for OTM options are smaller than those for ATM options. Results from Table V also show that percentages of stocks in the category of "Option to Stock" for OTM options are mostly bigger than those for ATM options. The only exception is for the pair of StockAggressiveSell and OptionVolatilityBuy in the "Option to Stock" category. Consistent with Lee and Yi (2001) and Chakravarty et al. (2004), my results provide evidence that informed option trading is more concentrated in OTM options resulting from their higher leverage effects.

To sum up, consistent with the prediction of the hypothesis, I find that the feedback effect exists between the aggressiveness variables of the stock limit order book and the option volatility trading variables. Further, I find that the percentage of stocks with Granger-causality running from stock aggressiveness variables to option volatility trading variables is higher at the beginning and at the end of the trading day, is generally higher for large than for small bidask spread, and is lower for OTM options than for ATM options.

\subsection{Variance Decompositions}

I also perform variance decompositions of each variable in the four-equation VAR and report the estimates of variance decompositions (\%), as well as the forecast standard errors estimated with 1,000 simulation runs for two forecast periods with two different variable orderings in Table VI. Consistent with the prediction of the hypothesis, I find that the stock aggressiveness variables and the option volatility trading variables can explain each other. 
TABLE VI

Variance Decompositions

\begin{tabular}{|c|c|c|c|c|c|}
\hline \multirow{2}{*}{$\begin{array}{l}\text { 5-Minute intervals } \\
\text { ahead }(n)\end{array}$} & \multirow{2}{*}{$\begin{array}{l}\text { Forecast } \\
\text { standard } \\
\text { error }\end{array}$} & \multicolumn{4}{|c|}{ Explanatory variable } \\
\hline & & StockAggressiveBuy & StockAggressiveSell & OptionVolatilityBuy & OptionVolatilitySell \\
\hline \multirow{2}{*}{\multicolumn{6}{|c|}{$\begin{array}{l}\text { Panel A: VAR ordering of StockAggressiveBuy, StockAggressiveSell, OptionVolatilityBuy, and } \\
\text { OptionVolatilitySell }\end{array}$}} \\
\hline & & & & & \\
\hline \multicolumn{6}{|c|}{ StockAggressiveBuy } \\
\hline 1 & 0.0086 & 100.00 & 0.00 & 0.00 & 0.00 \\
\hline 10 & 0.0096 & 96.29 & 3.70 & 0.01 & 0.01 \\
\hline \multicolumn{6}{|c|}{ StockAggressiveSell } \\
\hline 1 & 0.0085 & 3.82 & 96.18 & 0.00 & 0.00 \\
\hline 10 & 0.0096 & 9.75 & 90.24 & 0.00 & 0.00 \\
\hline \multicolumn{6}{|c|}{ OptionVolatilityBuy } \\
\hline 1 & 0.0096 & 0.00 & 0.00 & 100.00 & 0.00 \\
\hline 10 & 0.0096 & 0.04 & 0.05 & 99.65 & 0.26 \\
\hline \multicolumn{6}{|c|}{ OptionVolatilitySell } \\
\hline 1 & 0.0096 & 0.00 & 0.00 & 3.82 & 96.17 \\
\hline 10 & 0.0096 & 0.08 & 0.07 & 4.16 & 95.69 \\
\hline \multirow{2}{*}{\multicolumn{6}{|c|}{$\begin{array}{l}\text { Panel B: VAR ordering of OptionVolatilityBuy, and OptionVolatilitySell, StockAggressiveBuy, and } \\
\text { StockAggressiveSell } \\
\text { StockAgqressiveBuy }\end{array}$}} \\
\hline & & & & & \\
\hline StockAggressive & Buy & & & & \\
\hline 1 & 0.0086 & 100.00 & 0.00 & 0.00 & 0.00 \\
\hline 10 & 0.0096 & 96.28 & 3.69 & 0.01 & 0.01 \\
\hline \multicolumn{6}{|c|}{ StockAggressiveSell } \\
\hline 1 & 0.0085 & 3.82 & 96.18 & 0.00 & 0.00 \\
\hline 10 & 0.0096 & 9.75 & 90.24 & 0.00 & 0.01 \\
\hline \multicolumn{6}{|c|}{ OptionVolatilityBuy } \\
\hline 1 & 0.0096 & 0.00 & 0.00 & 100.00 & 0.00 \\
\hline 10 & 0.0096 & 0.04 & 0.05 & 99.65 & 0.26 \\
\hline \multicolumn{6}{|c|}{ OptionVolatilitySell } \\
\hline 1 & 0.0096 & 0.00 & 0.00 & 3.83 & 96.17 \\
\hline 10 & 0.0096 & 0.08 & 0.07 & 4.16 & 95.69 \\
\hline
\end{tabular}

Note. This table reports the variance decompositions of the aggressiveness of the stock limit order book and option volatility trading variables $n$ 5-minute intervals ahead, computed from a VAR with endogenous variables StockAggressiveBuy, StockAggressiveSell, OptionVolatilityBuy, and OptionVolatilitySell. The VAR is estimated with three lags. For each VAR, I report the estimates of variance decompositions (\%), as well as the forecast standard errors estimated with 1,000 simulation runs for two forecast periods. The sample includes the 529 stocks in both the NYSE OpenBook History (Openbook) database and the Options Price Reporting Authority (OPRA) database between November 1, 2007 and January 31, 2008. All variables used have been normalized. See Table I for variable definitions.

\subsection{Stock Skewness and Asymmetry in Buy Versus Sell Aggressiveness in Limit Order Book}

Table VII reports the results from a VAR with endogenous variables in the order of stock skewness and the asymmetry of buys versus sells in the limit order book, where I use stock return skewness, moneyness-based forward looking stock skewness, and volume-based forward looking stock skewness, respectively. Stock Return Skewness is the skewness of 5-minute stock return over the trading day. Moneyness is defined as the ratio of the strike price to the underlying stock price. Moneyness-Based Forward Looking Stock Skewness is the difference between the implied volatilities of an OTM put and an ATM call, where I choose one OTM put option with its moneyness closest to 0.95 and one ATM call option with its moneyness closest to 1. Volume-Based Forward Looking Stock Skewness is the difference between the option-volume weighted implied volatilities of OTM puts and ATM calls, where 
TABLE VII

Stock Skewness and Asymmetry in Aggressiveness of Buys Versus Sells in the Limit Order Book

\begin{tabular}{lcccc}
\hline & $\begin{array}{c}\text { Stock return } \\
\text { skewness }\end{array}$ & $\begin{array}{c}\text { Moneyness-based } \\
\text { forward looking } \\
\text { stock skewness }\end{array}$ & $\begin{array}{c}\text { Forward looking } \\
\text { Stock } \\
\text { skewness }\end{array}$ & $\begin{array}{c}\text { Asymmetry in } \\
\text { aggressiveness of stock } \\
\text { limit order book }\end{array}$ \\
\hline $\begin{array}{l}\text { Stock return skewness } \\
\text { Moneyness-based forward looking } \\
\text { stock skewness }\end{array}$ & & & $0.56^{n}$ \\
$\begin{array}{l}\text { Volume-based forward looking } \\
\text { stock skewness }\end{array}$ & & & 21.78 \\
$\begin{array}{l}\text { Asymmetry in aggressiveness of } \\
\text { stock limit order book }\end{array}$ & $0.86^{n}$ & 19.12 & 20.43 & 20.64 \\
\hline
\end{tabular}

Note. This table reports the results from a VAR with endogenous variables in the order of stock skewness and the asymmetry of buys versus sells in the limit order book. The VAR is estimated with three lags. Wald test statistics of pairwise Granger-causality tests are reported. The null hypothesis is that the row variable does not Granger-cause the column variable. Asymmetry in Aggressiveness of Stock Limit Order Book is StockAggressiveBuy minus StockAggressiveSell. Stock Return Skewness is the skewness of 5-minute stock return over the trading day. Moneyness is defined as the ratio of the strike price to the underlying stock price. Moneyness-Based Forward Looking Stock Skewness is the difference between the implied volatilities of an OTM put and an ATM call, where I choose one OTM put option with its moneyness closest to 0.95 and one ATM call option with its moneyness closest to 1. Volume-Based Forward Looking Stock Skewness is the difference between the option-volume weighted implied volatilities of OTM puts and ATM calls, where all OTM puts with moneyness between 0.80 and 0.95 , and all ATM calls with moneyness between 0.95 and 1.05 are used. Wald test statistics of pairwise Granger-causality tests between each skewness variable and the asymmetry in aggressiveness of Stock Limit Order Book are reported. Wald test statistics with a superscript $\mathrm{n}$ are not significant at the $10 \%$ level. Wald test statistics without any superscripts are significant at the $1 \%$ level. The sample includes the 529 stocks in both the NYSE OpenBook History (Openbook) database and the Options Price Reporting Authority (OPRA) database between November 1, 2007 and January 31, 2008.

all OTM puts with moneyness between 0.80 and 0.95, and all ATM calls with moneyness between 0.95 and 1.05 are used.

When there is upcoming bad news about the stock, informed stock limit order traders will sell the stock more aggressively. When there is upcoming good news about the stock, informed stock limit order traders will buy the stock more aggressively. So the asymmetry of buys versus sells in the limit order book reflects the upcoming perception of the stock. On the other hand, bigger forward looking skewness is associated with bad news about the future stock price, as option traders, if there is bad news about the stock, are more likely to buy put options than to short put options either for hedging or speculative purposes, which pushes up both the price and implied volatilities of the put. It is likely that option traders trade in response to the asymmetry of buys versus sells in the limit order book, and stock limit order traders trade in response to implied volatility skew. Consistently, results in Table VII show that only forward looking stock skewness (both moneyness-based and volume-based) and the asymmetry of buys versus sells in the limit order book Granger-cause each other.

\subsection{Impulse Response Functions}

To better understand the direction of the effect on the option volatility trading variables of a positive one-standard deviation shock to the stock aggressiveness variables and vice versa, I plot the impulse response functions in the four-equation vector autoregressions (VARs) with endogenous variables in the order of StockAggressiveBuy, StockAggressiveSell, OptionVolatilityBuy, and OptionVolatilitySell in Figure 2. The VAR is estimated using three lags selected as the least lag length indicated by the Akaike, Schwarz, and Hannan-Quinn information criteria. Plots of impulse response functions are generally consistent with the results of 
(A) Response of StockAggressiveBuy to OptionVolatilityBuy

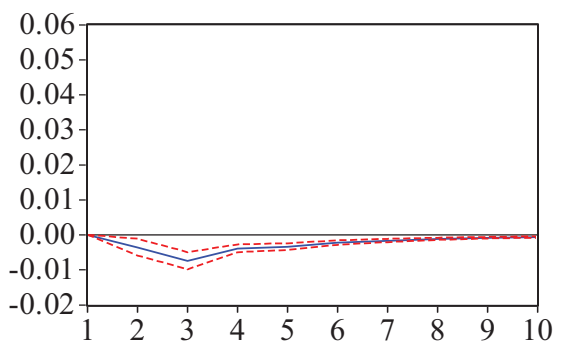

(C) Response of StockAggressiveSell to OptionVolatilityBuy

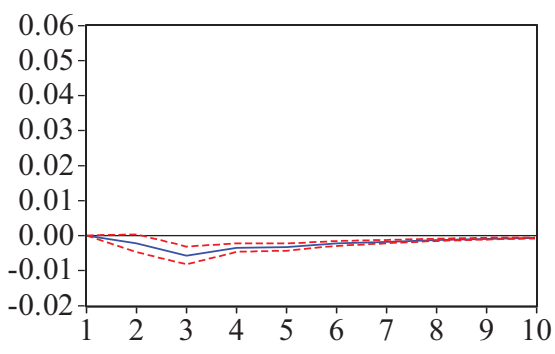

(E) Response of OptionVolatilityBuy to StockAggressiveBuy

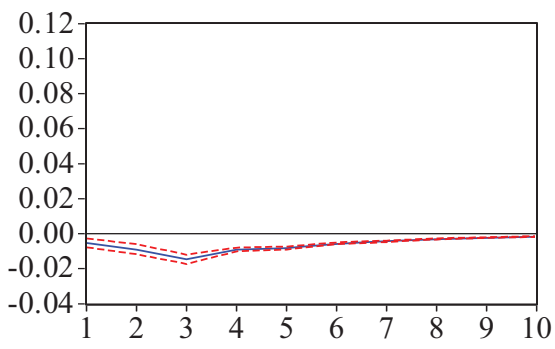

(G) Response of OptionVolatilitySell to StockAggressiveBuy

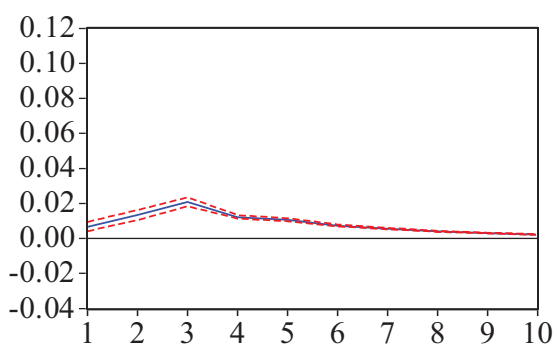

(B) Response of StockAggressiveBuy to OptionVolatilitySell

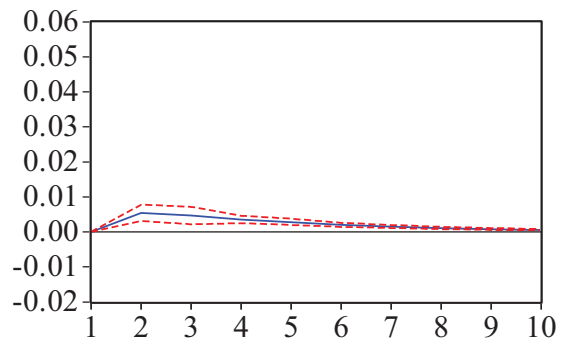

(D) Response of StockAggressiveSell to OptionVolatilitySell

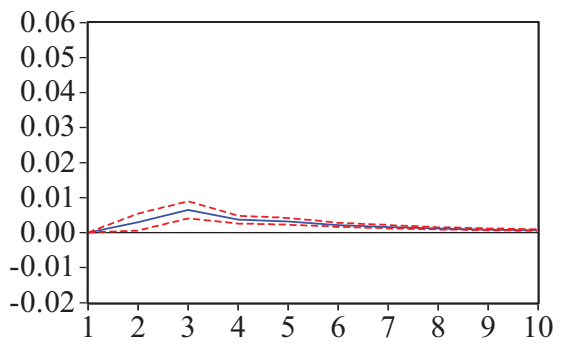

(F) Response of OptionVolatilityBuy to StockAggressiveSell

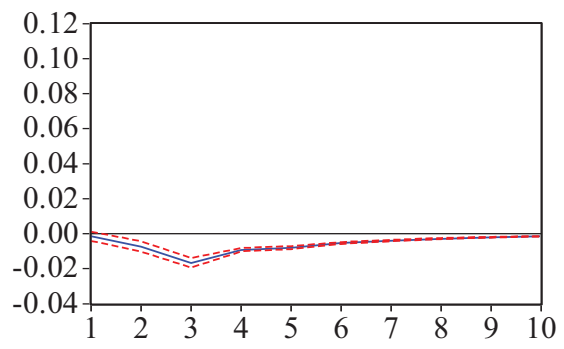

(H) Response of Option VolatilitySell to StockAggressiveSell

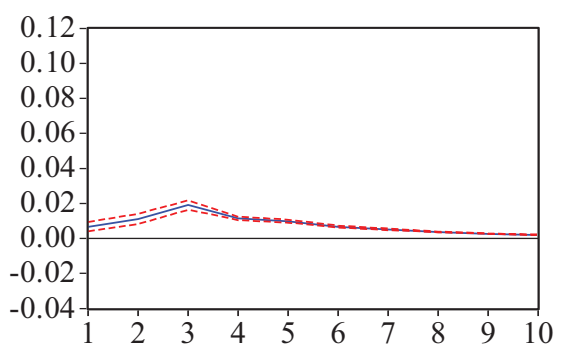

FIGURE 2

Impulse response functions.

Note. VAR with endogenous variables in the order of StockAggressiveBuy, StockAggressiveSell, OptionVolatilityBuy, and OptionVolatilitySell is estimates with three lags. I graph impulse responses (solid lines) of each variable along with corresponding two-standard-error bands (dashed lines). The error bands are based on Monte Carlo Integration with 1,000 simulations. Only normalized series are used in the VAR estimation. See Table I for variable definitions. [Color figure can be viewed in the online issue, which is available at wileyonlinelibrary.com.] 
Granger-causality tests, and can provide further views on the dynamic relationships between the endogenous variables. Monte Carlo two-standard-error confidence bands (based on 1,000 simulations) are also plotted to gauge the statistical significance of the impulse response functions. Contemporaneous response corresponds to period 1, whereas lagged responses correspond to subsequent periods. To conserve space, only impulse response plots of the VARs that are directly related to examining cross-market price discovery are reported. ${ }^{8}$

Panels A-D of Figure 2 plot responses of stock aggressiveness variables to shocks to option volatility trading variables. Panels E-H of Figure 2 plot responses of option volatility trading variables to shocks to stock aggressiveness variables. For example, Panels A and C of Figure 2 show that both StockAggressiveBuy and StockAggressiveSell decrease significantly in response to a positive one-time one standard deviation shock to OptionVolatilityBuy, with both responses reaching their troughs in period 3. The two-standard-error bands indicate that this result is highly significant. This provides evidence that volatility-informed stock traders place buy and sell orders less aggressively to minimize the picking off risk resulting from an increase in stock price volatility. Panel B of Figure 2 provides evidence that volatility-informed stock traders place buy orders more aggressively due to the diminishing picking off risk resulting from a decrease in stock price volatility. Similar supportive evidence can be gleaned from Panel D of Figure 2.

The impact of stock aggressiveness variables on option volatility trading is economically significant. For example, using the accumulated response over 10 periods (50 minutes) and assuming 250 trading days in a year and 78 five-minute intervals in a day, the effect of one standard deviation shock to StockAggressiveBuy on OptionVolatilitySell aggregates to an annualized amount of 80 million equity options contract volume, equivalent to an extra 10 days of options volume. ${ }^{9}$

In a word, consistent with the prediction of the hypothesis, I find that the aggressiveness variables of the stock limit order book is inversely related to option volatility buy and positively related to option volatility sell.

\section{ROBUSTNESS CHECKS}

I now check whether my Granger-causality findings are robust to including forward looking stock skew in the VAR. Specifically, the VAR with forward looking stock skew is

$$
\begin{aligned}
S_{t} & =\sum_{i=1}^{K} \alpha_{i} S_{t-i}+\sum_{i=1}^{K} \beta_{i} O_{t-i}+\sum_{i=1}^{K} \theta_{i} \text { Skew }_{t-i}+u_{t} \\
O_{t} & =\sum_{i=1}^{K} \gamma_{i} S_{t-i}+\sum_{i=1}^{K} \delta_{i} O_{t-i}+\varepsilon_{t}
\end{aligned}
$$

where $S_{t}$ is a 2 by 1 vector that represents the aggressiveness of the buy and sell sides of the stock limit order book, $O_{t}$ is a 2 by 1 vector that represents the option volatility trading. Skew is moneyness-based forward looking stock skewness or volume-based forward looking stock skewness. $K$ is the number of lags. The VAR is estimated with three lags based on the Akaike, Schwartz, and Hannan-Quinn information criteria.

Table VIII reproduces the main Granger-causality test results using the VAR controlling for moneyness-based forward looking stock skewness. It is obvious that my findings hold when

\footnotetext{
${ }^{8}$ Unreported impulse responses are available from the author upon request.

${ }^{9}$ Based on market statistics issued by CBOE, daily equity options contract volume on all U.S. options exchanges amounts to about 8 million in 2007. http://www.cboe.com/data/AnnualMarketStatistics.aspx.
} 
TABLE VIII

Robustness Checks: Granger-Causality Tests Controlling for Moneyness-Based Forward Looking Stock Skew

\begin{tabular}{|c|c|c|c|c|}
\hline & StockAggressiveBuy & StockAggressiveSell & nVolatilityBuy & OptionVolatilitySell \\
\hline \multicolumn{5}{|c|}{ Panel A: Pairwise Granger-causality tests } \\
\hline StockAggressiveBuy & & & 78.12 & 148.68 \\
\hline StockAggressiveSell & & & 110.46 & 167.35 \\
\hline Option VolatilityBuy & 32.06 & 15.62 & & \\
\hline Option VolatilitySell & 38.87 & 18.76 & & \\
\hline Time interval & Stock variable & Option trading variable & Stock to option & Option to stock \\
\hline \multicolumn{5}{|c|}{ Panel B: Pairwise Granger-causality tests by time of day } \\
\hline \multirow[t]{4}{*}{ 9:30 am-11:00 am } & StockAggressiveBuy & OptionVolatilityBuy & 13.88 & 12.08 \\
\hline & StockAggressiveBuy & Option VolatilitySell & 13.06 & 10.33 \\
\hline & StockAggressiveSell & OptionVolatilityBuy & 13.05 & 12.24 \\
\hline & StockAggressiveSell & OptionVolatilitySell & 14.21 & 13.07 \\
\hline \multirow[t]{4}{*}{$11: 00 \mathrm{am}-2: 30 \mathrm{pm}$} & StockAggressiveBuy & OptionVolatilityBuy & 10.96 & 7.99 \\
\hline & StockAggressiveBuy & OptionVolatilitySell & 9.23 & 7.01 \\
\hline & StockAggressiveSell & OptionVolatilityBuy & 10.26 & 7.05 \\
\hline & StockAggressiveSell & OptionVolatilitySell & 9.04 & 6.36 \\
\hline \multirow[t]{4}{*}{$2: 30$ pm-4:00 pm } & StockAggressiveBuy & OptionVolatilityBuy & 13.11 & 11.13 \\
\hline & StockAggressiveBuy & OptionVolatilitySell & 12.38 & 14.02 \\
\hline & StockAggressiveSell & OptionVolatilityBuy & 12.04 & 14.18 \\
\hline & StockAggressiveSell & OptionVolatilitySell & 13.17 & 16.14 \\
\hline
\end{tabular}

\begin{tabular}{ccccc}
\hline Moneyness & Stock variable & Option trading variable & Stock to option & Option to stock \\
\hline Panel C: Pairwise Granger-causality tests by & option moneyness & & \\
ATM & StockAggressiveBuy & OptionVolatilityBuy & 14.23 & 12.05 \\
& StockAggressiveBuy & OptionVolatilitySell & 16.01 & 10.22 \\
& StockAggressiveSell & OptionVolatilityBuy & 13.29 & 12.78 \\
& StockAggressiveSell & OptionVolatilitySell & 15.74 & 9.01 \\
ITM & StockAggressiveBuy & OptionVolatilityBuy & 10.16 & 8.79 \\
& StockAggressiveBuy & OptionVolatilitySell & 11.52 & 11.26 \\
& StockAggressiveSell & OptionVolatilityBuy & 14.08 & 13.05 \\
& StockAggressiveSell & OptionVolatilitySell & 15.21 & 10.59 \\
OTM & StockAggressiveBuy & OptionVolatilityBuy & 10.19 & 13.12 \\
& StockAggressiveBuy & OptionVolatilitySell & 10.24 & 12.79 \\
& StockAggressiveSell & OptionVolatilityBuy & 13.02 & 12.94 \\
& StockAggressiveSell & OptionVolatilitySell & 11.64 & 12.57
\end{tabular}

Note. This table reports the results from the following VAR: $S_{t}=\sum_{i=1}^{K} \alpha_{i} S_{t}-i+\sum_{i=1}^{K} \beta_{i} O_{t}-i+\sum_{i=1}^{K} \theta_{i} S k e w_{t}-i+u_{t}$, and $O_{t}=\sum_{i=1}^{K} \gamma_{i} S_{t}-i+\sum_{i=1}^{K} \delta_{i} O_{t}-i+\varepsilon_{t}$, where $S_{t}$ is a 2 by 1 vector that represents the aggressiveness of the buy and sell sides of the stock limit order book, $O_{t}$ is a 2 by 1 vector that represents the option volatility trading. Moneyness is defined as the ratio of the strike price to the underlying stock price. Skewis moneyness-based forward looking stock skewness defined as the difference between the implied volatilities of an OTM put and an ATM call, where I choose one OTM put option with its moneyness closest to 0.95 and one ATM call option with its moneyness closest to $1 . K$ is the number of lags. The VAR is estimated with three lags based on the Akaike, Schwartz, and Hannan-Quinn information criteria. In panel A, Wald test statistics of pairwise Granger-causality tests between each aggressiveness variable of the stock limit order book and each option volatility trading variable are reported. The null hypothesis is that the row variable does not Granger-cause the column variable. All the Wald test statistics are significant at the $1 \%$ level. Panel B reports the percentages of the stocks in the sample with statistically significant Granger-causality at the $5 \%$ level based on $F$-tests using three lags by time of day. "Stock to Option" means the aggressiveness variables of the stock limit order book Granger-causing the option volatility trading variables. "Option to Stock" means the option volatility trading variables Granger-causing the aggressiveness variables of the stock limit order book. Panel $\mathrm{C}$ reports the percentages of the stocks in the sample with statistically significant Granger causality at the $5 \%$ level based on F-tests using three lags by option moneyness. I define, respectively, in-the-money options as call options with moneyness less than 0.95 and put options with moneyness more than 1.05, out-of-the-money options as call options with moneyness greater than 1.05 and put options with moneyness less than 0.95 , at-the-money options with moneyness between 0.95 and 1.05, inclusively. All variables used have been normalized. See Table I for variable definitions. The sample includes the 529 stocks in both the NYSE OpenBook History (Openbook) database and the Options Price Reporting Authority (OPRA) database between November 1, 2007 and January 31, 2008. 
TABLE IX

Robustness Checks: Granger-Causality Tests Controlling for Volume-Based Forward Looking Stock Skew

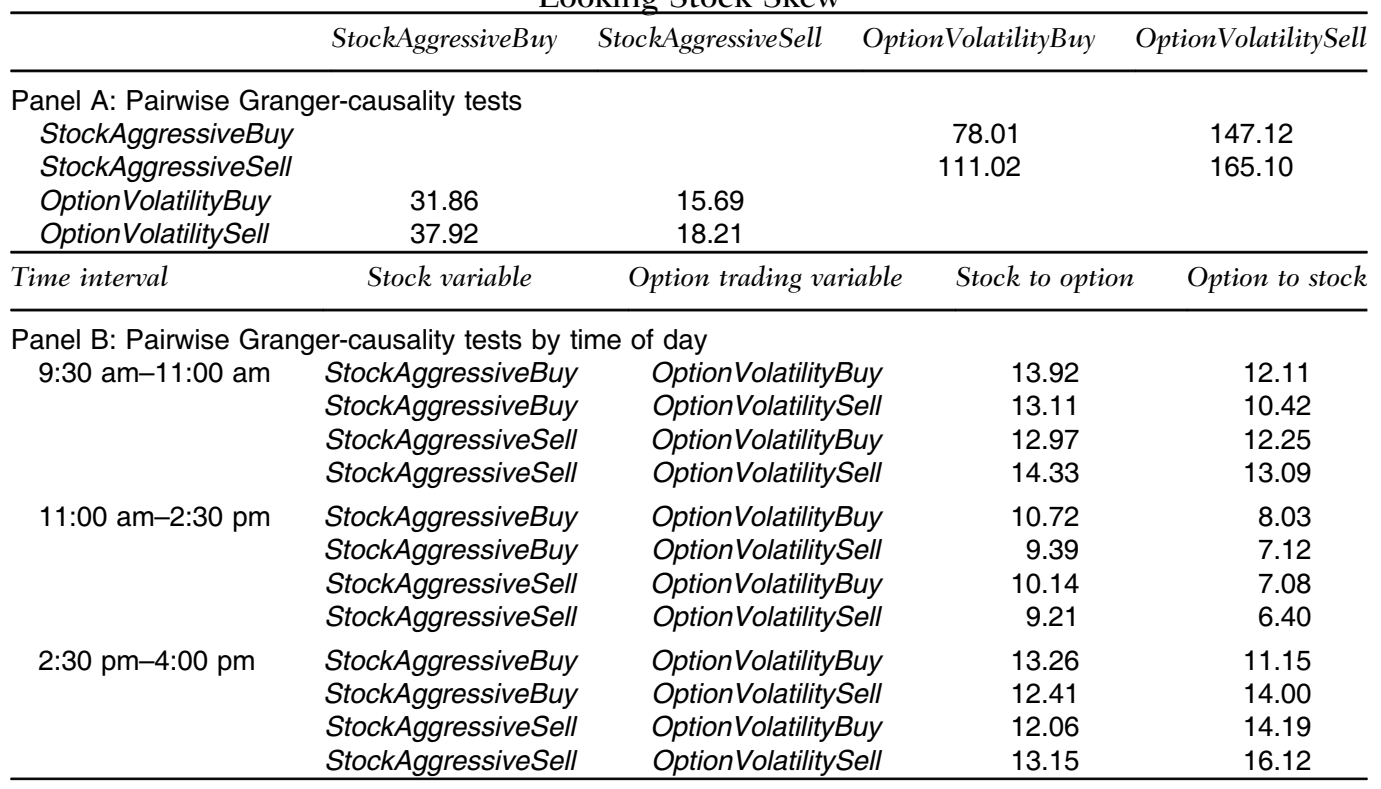

\begin{tabular}{ccccc}
\hline Moneyness & Stock variable & Option trading variable & Stock to option & Option to stock \\
\hline Panel C: Pairwise Granger-causality tests by option moneyness & OptionVolatilityBuy & 14.09 & 12.06 \\
ATM & StockAggressiveBuy & OptionVolatilitySell & 15.89 & 10.18 \\
& StockAggressiveBuy & Option & 13.27 & 12.66 \\
& StockAggressiveSell & OptionVolatilityBuy & 15.68 & 9.13 \\
ITM & StockAggressiveSell & OptionVolatilitySell & 10.14 & 8.74 \\
& StockAggressiveBuy & OptionVolatilityBuy & 11.50 & 11.12 \\
& StockAggressiveBuy & OptionVolatilitySell & 14.07 & 13.13 \\
& StockAggressiveSell & OptionVolatilityBuy & 15.18 & 10.51 \\
OTM & StockAggressiveSell & OptionVolatilitySell & 10.17 & 13.09 \\
& StockAggressiveBuy & OptionVolatilityBuy & 10.22 & 12.26 \\
& StockAggressiveBuy & OptionVolatilitySell & 13.02 & 12.83 \\
& StockAggressiveSell & OptionVolatilityBuy & 11.63 & 12.27
\end{tabular}

Note. This table reports the results from the following VAR: $S_{t}=\sum_{i=1}^{K} \alpha_{i} S_{t}-i+\sum_{i=1}^{K} \beta_{i} O_{t}-i+\sum_{i=1}^{K} \theta_{i} S k e w_{t}-i+u_{t}$, and $O_{t}=\sum_{i=1}^{K} \gamma_{i} S_{t}-i+\sum_{i=1}^{K} \delta_{i} O_{t}-i+\varepsilon_{t}$, where $S_{t}$ is a 2 by 1 vector that represents the aggressiveness of the buy and sell sides of the stock limit order book, $O_{t}$ is a 2 by 1 vector that represents the option volatility trading. Moneyness is defined as the ratio of the strike price to the underlying stock price. Skew is volume-based forward looking stock skewness defined as the difference between the option-volume weighted implied volatilities of OTM puts and ATM calls, where all OTM puts with moneyness between 0.80 and 0.95 , and all ATM calls with moneyness between 0.95 and 1.05 are used. $K$ is the number of lags. The VAR is estimated with three lags based on the Akaike, Schwartz, and Hannan-Quinn information criteria. In panel A, Wald test statistics of pairwise Granger-causality tests between each aggressiveness variable of the stock limit order book and each option volatility trading variable are reported. The null hypothesis is that the row variable does not Granger-cause the column variable. All the Wald test statistics are significant at the $1 \%$ level. Panel B reports the percentages of the stocks in the sample with statistically significant Granger-causality at the $5 \%$ level based on $F$-tests using three lags by time of day. "Stock to Option" means the aggressiveness variables of the stock limit order book Granger-causing the option volatility trading variables. "Option to Stock" means the option volatility trading variables Granger-causing the aggressiveness variables of the stock limit order book. Panel $\mathrm{C}$ reports the percentages of the stocks in the sample with statistically significant Granger causality at the $5 \%$ level based on $F$-tests using three lags by option moneyness. I define, respectively, in-the-money options as call options with moneyness less than 0.95 and put options with moneyness more than 1.05, out-of-the-money options as call options with moneyness greater than 1.05 and put options with moneyness less than 0.95 , at-the-money options with moneyness between 0.95 and 1.05 , inclusively. All variables used have been normalized. See Table I for variable definitions. The sample includes the 529 stocks in both the NYSE OpenBook History (Openbook) database and the Options Price Reporting Authority (OPRA) database between November 1, 2007 and January 31, 2008. 
TABLE X

Robustness Checks: Granger-causality Tests Controlling for Liquidity

\begin{tabular}{|c|c|c|c|c|}
\hline & StockAggressiveBuy & StockAggressiveSell & onVolatilityBuy & OptionVolatilitySel \\
\hline \multicolumn{5}{|c|}{ Panel A: Pairwise Granger-causality tests } \\
\hline \multicolumn{2}{|l|}{ StockAggressiveBuy } & & 73.55 & 116.89 \\
\hline \multicolumn{2}{|l|}{ StockAggressiveSell } & & 80.23 & 121.46 \\
\hline OptionVolatilityBuy & 31.56 & 9.37 & & \\
\hline Option VolatilitySell & 33.85 & 11.56 & & \\
\hline Time interval & Stock variable & Option trading variable & Stock to option & Option to stock \\
\hline \multicolumn{5}{|c|}{ Panel B: Pairwise Granger-causality tests by time of day } \\
\hline \multirow[t]{4}{*}{$9: 30 \mathrm{am}-11: 00 \mathrm{am}$} & StockAggressiveBuy & y OptionVolatilityBuy & 13.04 & 12.58 \\
\hline & StockAggressiveBuy & OptionVolatilitySell & 12.08 & 10.12 \\
\hline & StockAggressiveSell & OptionVolatilityBuy & 12.23 & 11.16 \\
\hline & StockAggressiveSell & OptionVolatilitySell & 14.13 & 13.09 \\
\hline \multirow[t]{4}{*}{$11: 00 \mathrm{am}-2: 30 \mathrm{pm}$} & StockAggressiveBuy & OptionVolatilityBuy & 9.22 & 7.03 \\
\hline & StockAggressiveBuy & OptionVolatilitySell & 7.52 & 6.34 \\
\hline & StockAggressiveSell & OptionVolatilityBuy & 8.06 & 6.21 \\
\hline & StockAggressiveSell & OptionVolatilitySell & 8.95 & 6.07 \\
\hline \multirow[t]{4}{*}{$2: 30$ pm-4:00 pm } & StockAggressiveBuy & OptionVolatilityBuy & 12.67 & 10.11 \\
\hline & StockAggressiveBuy & OptionVolatilitySell & 11.87 & 13.76 \\
\hline & StockAggressiveSell & OptionVolatilityBuy & 10.14 & 12.01 \\
\hline & StockAggressiveSell & OptionVolatilitySell & 13.17 & 14.89 \\
\hline \multicolumn{2}{|c|}{ Stock variable } & Option trading variable & Stock to option & Option to stock \\
\hline \multicolumn{5}{|c|}{ Panel C: Pairwise Granger-causality tests by option moneyness } \\
\hline \multirow[t]{4}{*}{ ATM } & IggressiveBuy & Option VolatilityBuy & 12.23 & 9.86 \\
\hline & IggressiveBuy & OptionVolatilitySell & 13.20 & 8.32 \\
\hline & ggressiveSell & Option VolatilityBuy & 10.75 & 12.13 \\
\hline & tggressiveSell & OptionVolatilitySell & 13.02 & 7.18 \\
\hline \multirow[t]{4}{*}{ ITM } & IggressiveBuy & OptionVolatilityBuy & 8.79 & 7.86 \\
\hline & IggressiveBuy & OptionVolatilitySell & 9.40 & 9.72 \\
\hline & Iggressive Sell & OptionVolatilityBuy & 10.35 & 10.79 \\
\hline & IggressiveSell & OptionVolatilitySell & 10.62 & 9.36 \\
\hline \multirow[t]{4}{*}{ OTM } & IggressiveBuy & OptionVolatilityBuy & 9.54 & 10.68 \\
\hline & IggressiveBuy & OptionVolatilitySell & 9.36 & 13.11 \\
\hline & IggressiveSell & OptionVolatilityBuy & 10.03 & 9.92 \\
\hline & IggressiveSell & OptionVolatilitySell & 9.92 & 11.83 \\
\hline
\end{tabular}

Note. This table reports the results from the following VAR: $S_{t}=\sum_{i=1}^{K} \alpha_{i} S_{t-i}+\sum_{i=1}^{K} \beta_{i} O_{t-i}+\sum_{i=1}^{K} \theta_{i} A m_{i h u d} d_{t-i}$ $\sum_{i=1}^{K} \vartheta_{i} D_{e p t} h_{t-i}+u_{t}$ and $O_{t}=\sum_{i=1}^{K} \gamma_{i} S_{t-i}+\sum_{i=1}^{K} \delta_{i} O_{t-i}+\varepsilon_{t}$, where $S_{t}$ is a 2 by 1 vector that represents the aggressiveness of the buy and sell sides of the stock limit order book, $O_{t}$ is a 2 by 1 vector that represents the option volatility trading, Amihud is the Amihud (2002) illiquidity measure defined as the ratio of the absolute stock return to its dollar volume over 5-minute intervals, Depth is the total size of the limit order book at the beginning of the 5-minute intervals, and $K$ is the number of lags. The VAR is estimated with three lags based on the Akaike, Schwartz, and Hannan-Quinn information criteria. In panel A, Wald test statistics of pairwise Granger-causality tests between each aggressiveness variable of the stock limit order book and each option volatility trading variable are reported. The null hypothesis is that the row variable does not Granger-cause the column variable. All the Wald test statistics are significant at the $1 \%$ level. Panel B reports the percentages of the stocks in the sample with statistically significant Granger-causality at the $5 \%$ level based on F-tests using three lags by time of day. "Stock to Option" means the aggressiveness variables of the stock limit order book Granger-causing the option volatility trading variables. "Option to Stock" means the option volatility trading variables Granger-causing the aggressiveness variables of the stock limit order book. Panel $\mathrm{C}$ reports the percentages of the stocks in the sample with statistically significant Granger causality at the $5 \%$ level based on $F$-tests using three lags by option moneyness. I define, respectively, in-the-money options as call options with moneyness less than 0.95 and put options with moneyness more than 1.05, out-of-the-money options as call options with moneyness greater than 1.05 and put options with moneyness less than 0.95 , at-the-money options with moneyness between 0.95 and 1.05 , inclusively. All variables used have been normalized. See Table I for variable definitions. The sample includes the 529 stocks in both the NYSE OpenBook History (Openbook) database and the Options Price Reporting Authority (OPRA) database between November 1 , 2007 and January 31, 2008. 
controlling for moneyness-based forward looking stock skewness. I also re-run the same tests using the VAR controlling for volume-based forward looking stock skewness and report results in Table IX. It is clear that the results also hold.

Among the many papers that explain optimal limit order placement for large traders (Subramanian \& Jarrow, 2001), Polimenis (2005) shows that liquidity is related to speed of execution and that illiquid markets are characterized by slow executions. Polimenis also reports that in such illiquid markets traders may prefer using aggressive limit orders in lieu of market orders to avoid the exposure to lengthy executions from the latter. To connect to such type of optimal behavior, I use the following VAR:

$$
\begin{aligned}
S_{t} & =\sum_{i=1}^{K} \alpha_{i} S_{t-i}+\sum_{i=1}^{K} \beta_{i} O_{t-i}+\sum_{i=1}^{K} \theta_{i} A_{m i h u d} d_{t-i}+\sum_{i=1}^{K} \vartheta_{i} \text { Depth }_{t-i}+u_{t} \\
O_{t} & =\sum_{i=1}^{K} \gamma_{i} S_{t-i}+\sum_{i=1}^{K} \delta_{i} O_{t-i}+\varepsilon_{t}
\end{aligned}
$$

where $S_{t}$ is a 2 by 1 vector that represents the aggressiveness of the buy and sell sides of the stock limit order book, $O_{t}$ is a 2 by 1 vector that represents the option volatility trading, Amihud is the Amihud (2002) illiquidity measure defined as the ratio of the absolute stock return to its dollar volume over 5-minute intervals, Depth is the total size of the limit order book at the beginning of the 5-minute intervals, and $K$ is the number of lags. The VAR is estimated with three lags based on the Akaike, Schwartz, and Hannan-Quinn information criteria.

Table X reports the Granger-causality findings using the above VAR and it is obvious that all my findings hold.

So far my results are based on 5-minute time aggregation. I now perform robustness checks of my results using 1-minute time aggregation.

Table XI reproduces pairwise Granger-causality test results using 1-minute time intervals. It is clear that all my findings are robust to using 1-minute time intervals. Unreported results using 1-minute time intervals show that the percentage of stocks with Granger-causality running from the stock aggressiveness variables to option volatility trading variables is higher at the beginning and at the end of the trading day, is generally higher for large than for small bid-ask spread, and is lower for OTM options than for ATM options.

Table XII reproduces pairwise variance decomposition results using 1-minute time intervals. Similar to results in Table VI, results in Table XII show that the stock aggressiveness variables can explain the variation in the option volatility trading variables and vice versa.

TABLE XI

Robustness Checks: Pairwise Granger-Causality Tests Using 1-Minute Time Intervals

\begin{tabular}{lcccc}
\hline & StockAggressiveBuy & StockAggressiveSell & OptionVolatilityBuy & OptionVolatilitySell \\
\hline StockAggressiveBuy & & & 117.48 & 149.58 \\
StockAggressiveSell & & & 111.49 & 171.61 \\
OptionVolatilityBuy & 34.13 & 16.32 & & \\
OptionVolatilitySell & 51.01 & 24.00 & & \\
\hline
\end{tabular}

Note. This table reports the results from a VAR with endogenous variables in the order of StockAggressiveBuy, StockAggressiveSell, OptionVolatilityBuy, and OptionVolatilitySell. The VAR is estimated with three lags. Wald test statistics of pairwise Granger-causality tests between each aggressiveness variable of the stock limit order book and each option volatility trading variable are reported. The null hypothesis is that the row variable does not Granger-cause the column variable. All variables used have been normalized. All the Wald test statistics are significant at the $1 \%$ level. See Table I for variable definitions except that I estimate snapshots of the limit order book at 1-minute intervals and construct variables similarly. 
TABLE XII

Robustness Checks: Variance Decompositions Using 1-Minute Time Intervals

\begin{tabular}{|c|c|c|c|c|c|}
\hline \multirow{2}{*}{$\begin{array}{l}\text { 1-minute intervals } \\
\text { ahead }(n)\end{array}$} & \multirow{2}{*}{$\begin{array}{c}\text { Forecast } \\
\text { standard } \\
\text { error }\end{array}$} & \multicolumn{4}{|c|}{ Explanatory variable } \\
\hline & & StockAggressiveBuy & StockAggressiveSell & OptionVolatilityBuy & OptionVolatilitySell \\
\hline \multicolumn{6}{|c|}{$\begin{array}{l}\text { Panel A: VAR ordering of StockAggressiveBuy, StockAggressiveSell, OptionVolatilityBuy, and } \\
\text { OptionVolatilitySell }\end{array}$} \\
\hline \multicolumn{6}{|c|}{ StockAggressiveBuy } \\
\hline 1 & 0.0078 & 100.00 & 0.00 & 0.00 & 0.00 \\
\hline 50 & 0.0097 & 93.39 & 6.58 & 0.01 & 0.01 \\
\hline \multicolumn{6}{|c|}{ StockAggressiveSell } \\
\hline 1 & 0.0075 & 1.01 & 98.99 & 0.00 & 0.00 \\
\hline 50 & 0.0098 & 8.24 & 91.75 & 0.01 & 0.01 \\
\hline \multicolumn{6}{|c|}{ OptionVolatilityBuy } \\
\hline 1 & 0.0099 & 0.00 & 0.00 & 99.99 & 0.00 \\
\hline 50 & 0.0099 & 0.03 & 0.03 & 99.81 & 0.13 \\
\hline \multicolumn{6}{|c|}{ OptionVolatilitySell } \\
\hline 1 & 0.0099 & 0.00 & 0.01 & 2.12 & 97.87 \\
\hline 50 & 0.0099 & 0.04 & 0.05 & 2.27 & 97.64 \\
\hline \multirow{2}{*}{\multicolumn{6}{|c|}{$\begin{array}{l}\text { Panel B: VAR ordering of OptionVolatilityBuy, and OptionVolatilitySell, StockAggressiveBuy, and } \\
\text { StockAggressiveSell }\end{array}$}} \\
\hline \multicolumn{3}{|c|}{ StockAggressiveBuy } & & & \\
\hline 1 & 0.0078 & 99.99 & 0.00 & 0.00 & 0.00 \\
\hline 50 & 0.0097 & 93.38 & 6.58 & 0.02 & 0.02 \\
\hline \multicolumn{6}{|c|}{ StockAggressiveSell } \\
\hline 1 & 0.0075 & 1.01 & 98.98 & 0.00 & 0.01 \\
\hline 50 & 0.0098 & 8.23 & 91.73 & 0.02 & 0.02 \\
\hline \multicolumn{6}{|c|}{ OptionVolatilityBuy } \\
\hline 1 & 0.0099 & 0.00 & 0.00 & 100.00 & 0.00 \\
\hline 50 & 0.0099 & 0.03 & 0.03 & 99.81 & 0.13 \\
\hline \multicolumn{6}{|c|}{ OptionVolatilitySell } \\
\hline 1 & 0.0099 & 0.00 & 0.00 & 2.12 & 97.88 \\
\hline 50 & 0.0099 & 0.04 & 0.04 & 2.28 & 97.65 \\
\hline
\end{tabular}

Note. This table reports the variance decompositions of the aggressiveness of stock limit order book and option volatility trading variables $n$ 1-minute intervals ahead, computed from a VAR with endogenous variables StockAggressiveBuy, StockAggressiveSell, OptionVolatilityBuy, and OptionVolatilitySell. The VAR is estimated with three lags. For each VAR, I report the estimates of variance decompositions (\%), as well as the forecast standard errors estimated with 1,000 simulation runs for two forecast periods. The sample includes the 529 stocks in both the NYSE OpenBook History (Openbook) database and the Options Price Reporting Authority (OPRA) database between November 1, 2007 and January 31, 2008. All variables used have been normalized. See Table I for variable definitions except that I estimate snapshots of the limit order book at 1-minute intervals and construct variables similarly.

\section{CONCLUSION}

This paper provides the empirical evidence on the volatility discovery across the aggressiveness of the stock limit order book and option volatility trading by showing that the two are informative for predicting each other. Further, I find that the aggressiveness of the stock limit order book is inversely related to option volatility buying and positively related to option volatility selling. The impact of the aggressiveness of the stock limit order book on option volatility trading is both statistically and economically significant. This is consistent with Foucault (1999) that limit order traders trade less aggressively due to increased picking off risk when perceived volatility is higher.

Taken together, my findings provide insights into the dynamic process of volatility discovery across the stock and options markets from a unique angle. In general, I show how 


\section{Volatility Discovery, Stock LOB, and Options}

the aggressiveness of the stock limit order book and option volatility trading interact with each other and demonstrate how the aggressiveness of the stock limit order book and option volatility trading play a dominant role in the dynamic volatility discovery. Finally, my results reemphasize that any study on volatility discovery across the stock and options markets ignoring limit order participation can suffer from significant bias.

\section{REFERENCES}

Ahn, H., Bae, K., \& Chan, K. (2001). Limit orders, depth, and volatility: Evidence from the stock exchange of Hong Kong. Journal of Finance, 56, 767-788.

Aitken, M., Almeida, N., deB. Harris, F. H., \& McInish, T. H. (2007). Liquidity supply in electronic markets. Journal of Financial Markets, 10, 144-168.

Amihud, Y. (2002). Illiquidity and stock returns: Cross-section and time-series effects. Journal of Financial Markets, $5,31-56$.

Amin, K., \& Lee, C. M. C. (1997). Option trading, price discovery, and earnings news dissemination. Contemporary Accounting Research, 14, 153-192.

Anthony, J. H. (1988). The Interrelation of stock and option market trading-volume data. Journal of Finance, 43, 949-961.

Anand, A., Chakravarty, S., \& Martell, T. (2005). Empirical evidence on the evolution of liquidity: Choice of market versus limit orders by informed and uninformed traders. Journal of Financial Markets, 8, 289-309.

Bae, K., Jang, H., \& Park, K. S. (2003). Traders' choice between limit and market orders: Evidence from NYSE stocks. Journal of Financial Markets, 6, 517-538.

Bagehot, W. (1971). The only game in town. Financial Analysts Journal, 27, 12-22.

Berkman, H. (1996). Large option trades, market makers, and limit orders. Review of Financial Studies, 9, 977-1002.

Biais, B., Hillion, P., \& Spatt, C. (1995). An empirical analysis of the limit order book and the order flow in the Paris Bourse. Journal of Finance, 50, 1655-1689.

Black, F. (1975). Fact and fantasy in the use of options. Financial Analysts Journal, 31, 36-72.

Black, F., \& Scholes, M. (1973). The pricing of options and corporate liabilities. Journal of Political Economy, 81, $637-654$.

Bloomfield, R., O’Hara, M., \& Saar, G. (2005). The make or take decision in an electronic market: Evidence on the evolution of liquidity. Journal of Financial Economics, 75, 165-199.

Cao, C., Chen, Z., \& Griffin, J. M. (2005). The informational content of option volume prior to takeovers. Journal of Business, 78, 1073-1109.

Cao, C., Hansch, O., \& Wang, X. (2009). The informational content of an open limit order book. Journal of Futures Market, 29, 16-41.

Chakravarty, S., Gulen, H., \& Mayhew, S. (2004). Informed trading in stock and option markets. Journal of Finance, 59, 1235-1257.

Chan, K., Chun, Y. P., \& Fong, W. (2002). The informational role of stock and option volume. Review of Financial Studies, 15, 1049-1075.

Cho, J., \& Nelling, E. (2002). The probability of limit-order execution. Financial Analysts Journal, 56, $28-33$.

Copeland, T., \& Galai, D. (1983). Information effects on the bid-ask spreads. Journal of Finance, 38, 1457-1469.

Cox, J., Ross, S. A., \& Rubinstein, M. (1979). Option pricing: A simplified approach. Journal of Financial Economics, 7, 229-263.

Easley, D., O’Hara, M., \& Srinivas, P. S. (1998). Option volume and stock prices: Evidence on where informed traders trade. Journal of Finance, 53, 431-465.

Figlewski, S., \& Webb, G. P. (1993). Options, short sales, and market completeness. Journal of Finance, 48, $761-777$.

Foster, F. D., \& Viswanathan, S. (1990). Variations in trading volume, return volatility, and trading costs: Evidence on recent price formation models. Journal of Finance, 48, 187-211.

Foucault, T. (1999). Order flow composition and trading costs in a dynamic limit order market. Journal of Financial Markets, 2, 99-134.

Foucault, T., Moinas, S., \& Theissen, E. (2007). Does anonymity matter in electronic limit order markets? Review of Financial Studies, 20, 1707-1747.

Glosten, L. R. (1994). Is the electronic open limit order book inevitable? Journal of Finance, 49, 1127-1161.

Glosten, L. R., \& Milgrom, P. R. (1985). Bid, ask and transaction prices in a specialist market with heterogeneously informed traders. Journal of Financial Economics, 14, 71-100.

Granger, C. W. J. (1969). Investigating causal relations by econometric models and cross-spectral methods. Econometrics, 37, 423-438. 
Granger, C. W. J. (1980). Testing for causality: A personal viewpoint. Journal of Economic Dynamics and Control, 2, $329-352$.

Griffiths, M., Smith, B., Turnbull, A., \& White, R. (2000). The costs and determinants of order aggressiveness. Journal of Financial Economics, 56, 65-88.

Handa, P., \& Schwartz, R. A. (1996). Limit order trading. Journal of Finance, 51, 1835-1861.

Harris, L., \& Hasbrouck, J. (1996). Market vs. limit orders: The superdot evidence on order submission strategy. Journal of Financial and Quantitative Analysis, 31, 213-231.

Harris, L., \& Panchapagesan, V. (2005). The information content of the limit order book: Evidence from NYSE specialist decisions. Journal of Financial Markets, 8, 25-67.

Hasbrouck, J., \& Saar, G. (2002). Limit orders and volatility in a hybrid market: The island ECN, Working paper, New York University.

Hollifield, B., Miller, R. A., Sandås, P., \& Slive, J. (2006). Estimating the gains from trade in limit order markets. Journal of Finance, 16, 2753-2804.

Kaniel, R., \& Liu, H. (2006). So what orders do informed traders use? Journal of Business, 79, 1867-1913.

Kavajecz, K. A. (1999). A specialist's quoted depth and the limit order book. Journal of Finance, 54, 747-771.

Kavajecz, K. A., \& Odders-White, E. R. (2004). Technical analysis and liquidity provision. Review of Financial Studies, 17, 1043-1071.

Kumar, R., Sarin, A., \& Shastri, K. (1992). The behavior of option price around large block transactions in the underlying security. Journal of Finance, 47, 879-889.

Kyle, A. S. (1985). Continuous auctions and insider trading. Econometrica, 53, 1315-1335.

Lamoureux, C. G., \& Lastrapes, W. D. (1993). Forecasting stock-return variance: Toward an understanding of stochastic implied volatilities. Review of Financial Studies, 6, 293-326.

Lee, C. M. C., \& Ready, M. J. (1991). Inferring trade direction from intraday data. Journal of Finance, 2, 733-746.

Lee, J., \& Yi, C. H. (2001). Trade size and information-motivated trading in the options and stock markets. Journal of Financial and Quantitative Analysis, 36, 485-501.

Linnainmaa, J. (2010). Do limit orders alter inferences about investor performance and behavior? Journal of Finance, $65,1473-1506$.

Lo, A. W., MacKinlay, A. C., \& Zhang, J. (2002). Econometric models of limit-order executions. Journal of Financial Economics, 65, 31-71.

Manaster, S., \& Rendleman, R. J. (1982). Option prices as predictors of equilibrium stock prices. Journal of Finance, 37, 1043-1057.

Mayhew, S., Sarin, A., \& Shastri, K. (1995). The allocation of informed trading across related markets: An analysis of the impact of changes in equity-option margin requirements. Journal of Finance, 50, 1635-1654.

Ni, S. X., Pan, J., \& Poteshman, A. M. (2008). Volatility information trading in option market. Journal of Finance, 63, 1059-1091.

Pan, J., \& Poteshman, A. M. (2006). The information in option volume for future stock prices. Review of Financial Studies, 19, 871-908.

Parlour, C. A., \& Seppi, D. J. (2008). Limit order markets: A survey. Handbook of Financial Intermediation \& Banking, 63-97.

Polimenis, V. (2005). A realistic model of market liquidity and depth. Journal of Futures Markets, 25, $443-464$.

Ranaldo, A. (2004). Order aggressiveness in limit order book markets. Journal of Financial Markets, 7, 53-74.

Schlag, C., \& Stoll, H. (2005). Price impacts of option volume. Journal of Financial Markets, 8, 69-87.

Seppi, D. (1997). Liquidity provision with limit orders and a strategic specialist. Review of Financial Studies, 10, $103-150$.

Stephan, J. A., \& Whaley, R. E. (1990). Intraday price change and trading volume relations in the stock and stock option markets. Journal of Finance, 45, 191-220.

Subramanian, A., \& Jarrow, R. A. (2001). The liquidity discount. Mathematical Finance, 11, 447-474.

Vijh, A. M. (1990). Liquidity of the cboe equity options. Journal of Finance, 45, 1157-1179. 